\title{
High-priority Tuberculosis Subject
}

National Cancer Institute

\section{Source}

National Cancer Institute. High-priority Tuberculosis Subject. NCI Thesaurus. Code C102644.

An individual that has tested positive for pulmonary, laryngeal, or pleural tuberculosis and may or may not present with cavitary disease. 